\title{
Demographic Profile and Childhood Morbidity Pattern in Western Nepal
}

\author{
Adhikari J ${ }^{1}$, Belbase $\mathrm{M}^{2}$, Bahl L ${ }^{3}$
}

\begin{abstract}
Background: Nepalgunj Medical College, is a tertiary care centre in western Nepal. This part of Nepal is under privileged with high rate of illiteracy and poverty leading to various morbidities including pediatric problems. This study is carried out as there have not been much studies with this regard specially from this part of the country. Methods: This is a retrospective study done in patients admitted in pediatric ward of Nepalgunj Medical College, Kohalpur, for six months from June to November 2014. Results: Out of 949 patients admitted in Nepalgunj Medical College, Kohalpur, 604 (63.6\%) were male and 345(36.4\%) were female. Age range 1-5 years had the maximum number of patients $342(36 \%)$ of the total hospital admissions. Respiratory tract infections were the most frequent cause of childhood morbidity 266 (28\%) followed by central nervous system illness 138 (14.5\%) and gastrointestinal system illness $122(12.9 \%)$. Mean hospital stay was 4.3 days. Conclusions: Respiratory tract infections were the most frequent cause of childhood morbidity $266(28 \%)$ followed by central nervous system illness $138(14.5 \%)$ and gastrointestinal system illness $122(12.9 \%)$.
\end{abstract}

Keywords: Childhood morbidity, Nepalgunj Medical College

\section{INTRODUCTION}

Nepalgunj Medical College, being a tertiary care centre in western Nepal, entertains patients from mid-western and farwestern regions of western Nepal. Western Nepal is under privileged with high rate of illiteracy and poverty leading to various morbidities in general and pediatric population is no exception. An understanding of the epidemiological trend in hospital admissions, including morbidity pattern is critical for healthcare planning and appropriate resource allocation. Ninety percent of children in the early $21^{\text {st }}$ century are born into the developing countries.

According to World Health Organization (WHO), 10.5 million children younger than 5 year died in 1999. Of these, $99 \%$ lived in developing countries. Worldwide, children younger than 15 years comprises of $28 \%$ of total population ${ }^{1}$.

Among the pediatric population, under five morbidity and mortality are very high. As per the World Health Organization report 2012, Nepal has neonatal mortality of 24/1000 live birth, infant mortality of 34/1000 live birth and under five mortality is 42/1000 live birth ${ }^{2}$. These indicators are higher than figures from well to do countries and it's a big challenge

\footnotetext{
1. Dr. Jyoti Adhikari

2. Dr. Mohan Belbase

3. Dr. Lalita Bahl
}

Address for correspondence:

Dr. Jyoti Adhikar

Department of Paediatrics

Nepalgunj Medical College Teaching Hospital, Kohalpur, Banke, Nepal

Email: adhikarijyoti@yahoo.com not only to the government but also to all the medical personals working in child health. This study is carried out as there have not been much studies with this regard specially from western part of the country.

\section{MATERIALS AND METHODS}

This is a retrospective study carried out at pediatric ward of Lord Buddha Educational Academy, Nepalgunj Medical College Teaching Hospital, Kohalpur, Banke over a period of 6 months from June to November 2014. Total 949 cases were admitted in the pediatric ward during that period. Patients were admitted from emergency room and pediatric out patient department and were attended and managed by pediatric residents and pediatricians.

The details of each case were taken from patients case records. Name, age, sex, address, ethnicity, date of admission, duration of hospital stay and diagnosis were recorded from the record file. Patients who were referred from emergency department were excluded from the study. The data so collected was subjected to standard statistical analysis.

\section{RESULTS}

A total of 949 patients were admitted during the study period out of which $604(63.6 \%)$ were male and 345(36.4\%) were female as shown in Figure 1. 


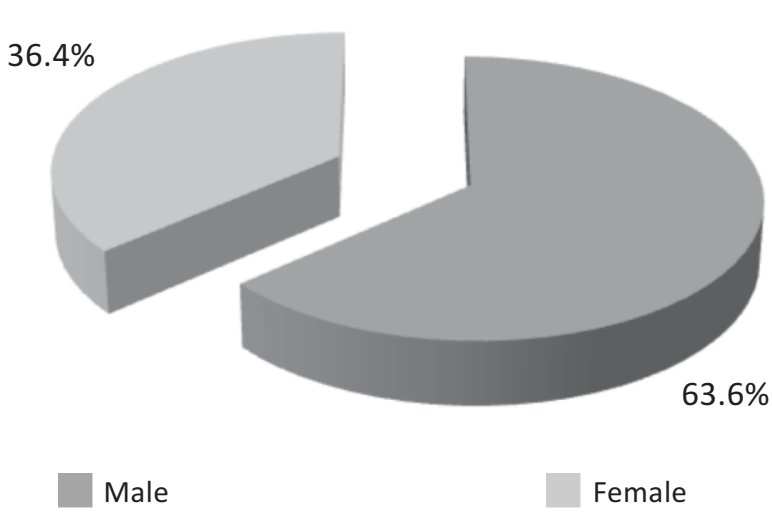

Figure 1. Sex distribution of the patients.

\begin{tabular}{|l|c|c|}
\hline Age (years) & No. of patients & Percentage \\
\hline 1month - 1year & 234 & 24.7 \\
\hline $1-5$ & 342 & 36 \\
\hline $6-10$ & 193 & 20.3 \\
\hline $11-14$ & 180 & 19 \\
\hline Total & 949 & 100 \\
\hline
\end{tabular}

Table I. Age distribution of the patients

As shown in Table 1, out of 949 patients, age group between 1-5 years had the maximum number of patients i.e, $342(36 \%)$ whereas age groups of 11-14 had the least number of patients 180(19\%).

\begin{tabular}{|l|c|c|}
\hline Ethnicity & No. of patients & Percentage \\
\hline Tharu & 235 & 24.8 \\
\hline Brahmnin & 165 & 17.4 \\
\hline Chhetri & 259 & 27.3 \\
\hline Gurung & 47 & 4.9 \\
\hline Others & 243 & 25.6 \\
\hline Total & 949 & 100 \\
\hline
\end{tabular}

Table II. Ethnicity distribution of the patients.

As shown in Table II. Chhetri accounted for the majority of population which consisted of $259(27.3 \%)$ patients.

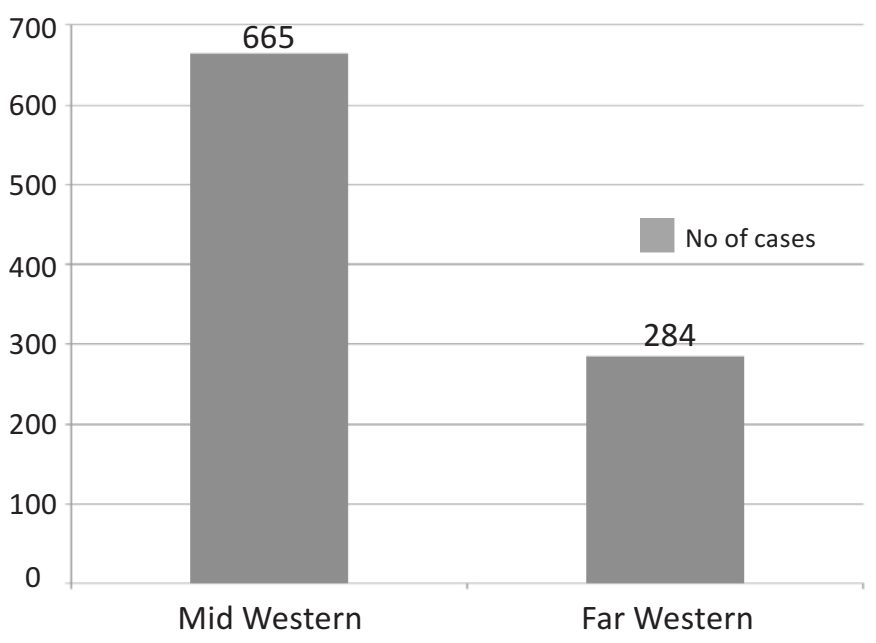

Figure.2 Figure showing geographic distribution of patients.

As shown in Fig. 2 maximum number of patients seeking medical attention came from mid-western region of Nepal accounting for $665(70 \%)$ patients. Rest $284(30 \%)$ were from the far-western region.

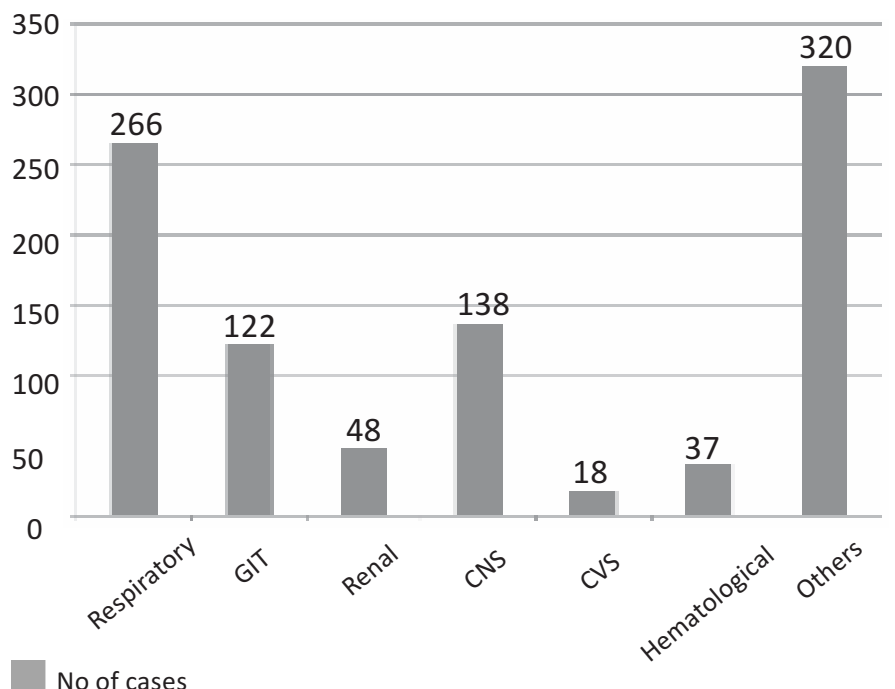

Fig. 3: Showing system wise distribution of disease among patients.

As shown in Figure 3 in the system wise distributions, respiratory tract infections were the most frequent cause of childhood morbidity requiring hospital admission. Total number of patients with respiratory diseases were 266(28\%) out of which pneumonia accounted for the most common childhood illness 227(85.3\%) patients followed by bronchiolitis $16(6 \%)$, tuberculosis $16(6 \%)$ and bronchial asthma $7(2.7 \%)$ patients.

Gastrointestinal system illness comprised of $122(12.9 \%)$ patients out of which diarrheal diseases accounted for majority 
of hospital admissions $98(80.3 \%)$ followed by viral hepatitis 19 (15.6\%) and Kochs abdomen 5(4.1\%). Renal system comprised of $48(5.1 \%)$ patients. Patients with nephrotic syndrome were 18(37.5\%), post-streptococcal glomerulonephritis 12(25\%) and urinary tract infection $18(37.5 \%)$. Central nervous system involved 138(14.5\%) patients out of which seizure disorder 60 (43.5\%) accounted for most admissions. In the seizure disorder most of the patient were of neurocysticercosis followed by tuberculoma. Acute encephalitis syndrome accounted for 33 (23.9\%) patients, followed by meningitis $23(16.7 \%)$ and febrile convulsion 22(15.9\%) patients.

Cardiovascular system related illness represented $18(1.9 \%)$ out of which Congenital heart disease comprised of $13(72.2 \%)$ and rheumatic heart disease $5(27.8 \%)$ patients. There were $37(3.9 \%)$ cases of hemolytic anemia with the most frequent diagnosis of thalasseamia, Other cases were with sickle cell anemia, aplastic anemia and G6PD deficiency. Other illness 320 (33.7\%) included enteric fever, malaria, kala-azar, poisoining, septicemia, severe protein energy malnutrition, malignancy etc. The minimum number of hospital stay was 1 day and maximum was 38 days with a mean of 4.3 days.

\section{DISCUSSION}

Out of 949 patients, 604(63.6\%) were male and 345(36.4\%) were female. This gender distribution is similar to the study done in Lumbini zonal hospital pediatric inpatients in which out of 977 admitted children, 579(59\%) were males and 398(41\%) females ${ }^{3}$. In another similar study carried out in Kathmandu at a private medical college, out of 453 patients admitted during the study period, there were $267(59 \%)$ male and $186(41 \%)$ female children ${ }^{4}$.

In another study done in West Indies, out of 1350 admissions there were 570 female and 715 male with $p<0.0015$. This gender disparity could be due to preference given to the male child over female while seeking treatment as such gender bias is widely prevalent in our catchment area.

Age range of 1-5 years had the maximum number of patients i.e, $342(36 \%)$ of the total hospital admissions. This result is similar to the study done in Nepal Medical College where less than five years age group accounted for 180 (39.7\%) excluding the neonate ${ }^{4}$. Ethnic distribution was as per the distribution of national and regional population distribution given by the central bureau of statistics, government of Nepal in which the most common ethnicity is Chhetri ${ }^{6}$. Our finding consisted of 259 (27.3\%) Chhetri patients followed by others 243 (25.6\%) and $235(24.8 \%)$ Tharu patients.

Most of patients seeking medical attention came from midwestern region of Nepal accounting for 665 (70\%) and 284 $(30 \%)$ were from the far-western region. This is due to midwestern location and thus more respective catchment area of this hospital. respiratory tract infections were the most frequent cause of childhood morbidity requiring hospital admission representing $266(28 \%)$ of patients out of which pneumonia accounted for $227(85.3 \%)$, followed by bronchiolitis $16(6 \%)$, tuberculosis 16 (6\%) and bronchial asthma $7(2.7 \%)$. This is similar to the study done in Lumbini zonal hospital where 309(31.6\%) patients comprised of respiratory tract infections including pneumonia, acute bronchiolitis and asthma ${ }^{3}$. This finding of respiratory disease being number one is similar to other studies done in Kathmandu Medical college and Dhulikhel Hospital ${ }^{7,8}$.

Gastrointestinal system illness comprised of 122(12.9\%) patients out of which diarrheal diseases accounted for majority of hospital admissions 98 (80.3\%). This finding is bit lower than findings in another similar study where diarrhoeal diseases contributed $112(24.7 \%)$ of pediatric morbidity ${ }^{4}$. Being a tertary care centre, this could be due to lower number patients coming up with acute problems like diarrhoeal disease which is widely treated in health post and sub-health post levels across the country.

Central nervous system involved $138(14.5 \%)$ patients with seizure disorder 60(43.5\%) accounting for most of the hospital admissions. Among seizure disorder most of the patient had neurocysticercosis and tuberculoma. Acute encephalitis syndrome accounted for $33(23.9 \%)$ patients, followed by meningitis $23(16.7 \%)$ and febrile convulsion $22(15.9 \%)$ patients. This is similar to the study done in Nepal Medical College in which CNS diseases comprised of $43(9 \%)$ of which $7(16 \%)$ were meningitis and meningoencephalitis and $26(60 \%)$ had febrile convulsion. In another study done regarding childhood neurological disorders, it was found that febrile encephalopathies, neurocysticercosis and epilepsy were the most frequent neurological problems in Nepalese children?

In our finding, central nervous system problems are more common than gastrointestional illnesses and the reason could be getting more chronic and severe looking illnesses like seizures in such tertary care centre more often than easily treatable and less complicated appearing diarrhoeal diseases.

Cardiovascular system related illness represented $18(1.9 \%)$ out of which congenital heart disease comprised of $13(72.2 \%)$ and rheumatic heart disease $5(27.8 \%)$ patients. This finding is similar to the study done in Lumbini zonal hospital where cardiac patients were $15(1.5 \%)^{3}$.

There were $37(3.9 \%)$ cases of hemolytic anemia with most frequent diagnosis of thalasseamia. Other cases were with sickle cell anemia, aplastic anemia and G6PD deficiency. As thalassemia is more common in Tharu population, more rigorous studies needs to be done with this regards. In one study, though not studied hemolytic anemia separately, childhood anemia in less than 5 years was found to be $46 \%$ in children attending to hospital OPD ${ }^{10}$. 
with a mean of 4.3 days. This finding is comparable with the study done in Lumbini zonal hospital where $85 \%$ patients stayed in hospital for 5 days or less ${ }^{3}$.

\section{CONCLUSION}

Out of 949 patients admitted during the study period, $604(63.6 \%)$ were male and 345(36.4\%) were female. Age range 1-5 years had the maximum number of patients i.e, $342(36 \%)$ of the total hospital admissions.

Respiratory tract infections were the most frequent cause of childhood morbidity $266(28 \%)$ followed by central nervous system illness $138(14.5 \%)$ and gastrointestinal system illness $122(12.9 \%)$. Mean hospital stay was 4.3 days. These findings can be implicated in management of childhood illnesses in this region but more rigorous community studies with large sample size needed to elaborate the exact pediatric morbidity patterns from western Nepal.

\section{ACKNOWLEDGEMENT}

My sincere thanks to pediatric ward sisters and interns who helped me to retrieve data from the record book. Thanks to department of pediatrics, my colleagues and my teachers for their encouragement and logistic help.

\section{REFERENCES}

1. Bonita FS, Richard EB. Overview of Pediatrics: In kligeman RM, Behrman RE, Schor NF, St. Geme III JW and Santon BF. Nelson Textbook of Pediatrics. $19^{\text {th }}$ ed. Philadelphia: W.B. Saunders Company; 2011:1-13.

2. World Health Organization. World Health Statistics 2014: [ Cited Nov 2 2014] Available from http://apps.who.Int/ iris/bitstream/10665/112738//1/9789240692671_eng.pdf.

3. Paudel KM, Sharma S. Review of Paediatrics Inpatient at a Zonal Hospital. J. Nepal paediatr. Soc. Sep-Sec 2012; 32 (3):239-44.

4. Upadhaya S, Sharma A, Risal P, Shrestha S. Review of Paediatric In patients at Nepal Medical College and Teaching hospital. J. Nepal paediatr. Soc. 2010; 31 (1):25-29.

5. Eck C, Peirre RB, Hambleton IR. Medical pediatrics admission patterns at the University Hospital of the West Indies: issues for future planning. West Indian med J. Oct 2006;55(5).

6. Government of Nepal, National planning commission secretariat, central bureau of statistics. July 42011.

7. Bajracharya BL, Joshi $P$, Manandhar DS, Baral MR. Review of Pediatrics in Patients at Kathmandu Medical College. J Kathmandu Med Col. 2002;4:43-49.

8. Nepali N, Ghimire R, Shrestha RPBS. Review of pediatrics Inpatients at Dhulikhel Hospital, Kathmandu University Teaching Hospital. J Nepal Paedtr Soc 2007;26:16-19.

9. Mishra N, Belbase M, Shrestha D, Paudel R, Mishra P. Childhood neurological illness in Nepal. Journal of Nepal Health Research Council. April 2010; 8(1).

10. Bajracharya BL, Manandhar DS, Baral MR. Hemoglobin status in the children age group 6 to 60 months. J Nep Med Assoc. 2006; 45:190-195. 